\title{
POÉTICAS AFRO-BRASILEIRAS, UM LIVRO QUE FAZIA FALTA
}

Maria Aparecida Santilli

Universidade de São Paulo

C

om o título atrativo de Poéticas afro-brasileiras (Belo Horizonte, Maza/

PUC - Minas, 2002, 259 páginas), Maria do Carmo Lanna Figueiredo e Maria Nazareth Soares Fonseca, as organizadoras desta coletânea, reuniram doze textos de diversos autores entre os quais elas próprias se incluem. Nesta contagem computou-se a "Introdução". Vem assinada por elas e vale como matéria primeira onde se levanta a questão de fundo em torno da qual os textos, de uma forma ou de outra, se constroem: a da literatura como um "importante lugar de denúncia e resistência dos negros" que, considerando como contexto o Brasil, leva estes autores a problematizarem "os modos como a cultura brasileira enfrenta o espetáculo de cores".

São textos concertados por uma nota, a da convicção e decorrente combatividade dos autores, que especialmente suscita o reconhecimento e leva à adesão do leitor que porventura ainda não tivesse vivido alguma experiência nessa direção.

Sabe-se que um discurso literário só se impõe quando, de saída, vem com os requisitos indispensáveis da lógica interna e das inflexões da literariedade que lhe conferem as propriedades de convencer e comover. O grande problema do discurso analítico ou crítico é o de fazer a mediação entre a obra e o público sem que na metalinguagem se perca-o calor das qualidades literárias de que trata.

Pois os ensaístas desta coletânea lavraram um tento, ao falarem de um motivo, de uma prática afro-brasileira que resgatam, ou deles tratarem via escritores escolhidos. Mantiveram a candência, a pulsação energética que 
lhes foi passada e que decerto também se deve à sua condição de comparticipantes da mesma causa, imagem que coletivamente transita ou transitará aos que agora tiverem acesso a poéticas afro-brasileiras.

O primeiro texto é de Luiz Silva (Cuti) e logo ganha interesse por inserir, pertinentemente, um tópico específico que falta no leque da estética da recepção, sobretudo quando se considera a realidade do Brasil: "O leitor e o texto afro-brasileiro". Cuti é convenientemente realista em apontar a ausência do leitor negro no horizonte de expectativas da maioria dos escritores brasileiros e necessariamente pragmático ao avançar na proposta de ocupação do espaço que cabe à prática e teoria da literatura negra brasileira.Questões como essas não costumam ser objeto comum de ocupação entre intelectuais que navegam nas águas da literatura.

Com endereço certo para seu público imediato, que é evidentemente o brasileiro, Cuti convida a pensar que a realização dessa proposta "implica e projeta uma nova subjetividade no país, em cuja tarefa o exercício de estar no lugar do outro consiste, para a nacionalidade, em estar em si mesma, através da empatia com o ser negro e o despojamento da brancura ou, ainda, a fase conflitiva para se chegar a isso" (p.28).

O ponto de chegada de suas reflexões revela o nível de consciência na síntese que determina o alcance maior:

\footnotetext{
À literatura negra brasileira não cabe a idealização fácil. Pelo contrário, é seu papel fundamental desidealizar o negro e o branco, investindo contra os estereótipos, e demonstrar que nem tudo o que seduz é branco, captando os movimentos sinuosos da ideologia racista na variada gama de situações sociais. (p. 34)
}

Os dois capítulos seguintes, "Cantopoemas: uma literatura silenciosa no Brasil" e "Discursos identitários afro-brasileiros: o Ilê-Aiyê", respectivamente de Edimilson de Almeida Pereira e Florentina Souza, tratam de práticas culturais , como é a do congado - no primeiro deles - e, depois, a do grupo artístico de Salvador, cujo nome se tornou conhecido desde sua militância na Bahia.

Quanto aos "Cantopoemas", entre muitas informações que permitem divulgar e aprofundar conhecimentos sobre o rito do congado, mencionemse: a textualidade banto-católica 
nasce do esforço de indivíduos negros e mestiços que transformam o silêncio e o isolamento em matérias do canto e da celebração; [...]A literatura silenciosa diz respeito a um aspecto da textualidade que, mesmo condenada ao exílio, aponta várias janelas para a atribuição de sentido ao mundo. $\mathrm{O}$ exílio se torna parcial na medida em que a literatura silenciosa estremece os cultores do cânone, que a percebem como algo a ser repelido devido a seu estranhamento, mas, por causa da diferença, também como algo a ser buscado para introduzir no "já conhecido" a perspectiva de renovação. (p.41)

Edimilson aponta, também, para o outro lado funcional da "literatura silenciosa", o de que ela "constitui lugar a partir do qual os indivíduos destituídos de voz, por força das desigualdades sociais, estabelecem sua autorepresentação” (p.42). Desta forma, a análise do congado, passando por seus vários sentidos, remete a revê-lo como "espelho dos vários processos de interação e conflito que marcam a sociedade brasileira” (p.53).

Florentina Souza começa por contextualizar o IlÊ-Aiyê no espaço que foi propício ao seu florescimento, Bahia/Salvador, dado o grande contingente negro e os correlativos fatos históricos, sociais e políticos que aí marcaram a vida da população de origem africana, inclusive, portanto, os de ordem cultural, quanto aos quais ela rememora a mestiçagem, por um lado, e "a capacidade de resistência e da habilidade de negociação identitárias”, por outro (p. 83). Relembra, ainda: “Como civilizações em que predomina a oralidade, as africanas têm nos cânticos e no estabelecimento de circuitos de produção e de trânsito das expressões de sentimento, emoções e anseios, importante veículo de comunicação e informação” (p. 84-85). Ligando a expressão musical local a outras, aos blues, ao jazz ao reggae, ao soul, aos "chamados ritmos caribenhos", ao ijexá, ao rap, entre outras, ela contextualiza as manifestações do tipo do Ilê-Aiyê nas formas universais de “resistência, de protesto, rebeldia e afirmação” dos afro-descendentes.

Assim o bloco afro-brasileiro Ilê-Aiyê , pelas letras das músicas, se inscreve "em uma linha criativa da diáspora que evidencia o desejo de promover a reconfiguração da auto-estima e a elaboração de outro sistema de representação dos afrodescendentes", bem como o "redesenho afirmativo de laços culturais com a África gestados nos intensos trânsitos e nas sofri- 
das, dolorosas e criativas trocas no "Atlântico Negro", além da reconstrução da atuação histórica e da memória do afro-brasileiro" (p. 87).

Os quatro capítulos seguintes dedicam-se a analisar diferentes autores.

Jussara Santos trata de "Talvez negro (por que não vermelho?): detalhes de um Mário arlequinal". "No contexto da conturbada formação brasileira”, que aí traça, propõe-se a pensar "momentos da poética de Mário de Andrade, esse que acredita ser um arlequim em nossa 'geléia geral”' (p. 101).

Pela análise dos poemas que apresenta, vai procurando focalizar como a questão da mestiçagem ou mistura de "raças" aparece nas composições do escritor modernista, acabando por enfatizar maneiras pelas quais ele tentou entender o imbroglio da questão étnica em si, no Brasil: "Creio que o escritor Mário de Andrade buscou constantemente pensar sua identidade. Quem é Mário, quem sou eu, quem somos nós?” (p. 114).

Kátia da Costa Bezerra fala sobre "A cor da ternura: tecendo os fio da memória”. Como se anuncia no título, privilegiando escritas autobiográficas aqui se trabalha sobre o percurso de criação que se efetiva com a "articulação estabelecida entre a experiência pessoal e coletiva, o ficcional e o real num jogo que permite a desconstrução de uma ordem simbólica opressiva, propondo, em seu lugar, novas formas de saber, de pensar" (p.120). A vivência focalizada no livro de Geni Mariano Guimarães aqui visto, no círculo do mais próximo contexto social permite que se contraponha a visão do quotidiano das famílias negras a outras perspectivas estereotipadas, assim como, revelando a passagem deste para outros espaços mais amplos já através da escola, promove, na protagonista, o reconhecimento de sua "diferença" pelos índices de preconceito de que progressivamente se vai dando conta.

"A cor da ternura" coloca-se, então, como um livro onde se visibiliza "o caráter violento presente na relação senhor versus escravo e as estratégias de luta, dos momentos de revolta organizada”. Pelas peculiaridades dos diferentes grupos de escravos vindos para o Brasil, o livro de Geni Mariano Guimarães encaminharia "a uma reconstrução do passado e, consequentemente, a uma revisão da simbologia da nação" (p. 126). Na narrativa autobiográfica, por englobar, portanto, duplo foco de visão, rememorando e refletindo sobre o que se passou, moldada, segundo Kátia da Costa Bezerra, "entre sujeito e sociedade, entre sujeito e cultura, entre o sujeito e o Outro (p. 130), perfazendo-se o movimento de resgatar, (re)significar e legitimar outras possibilidades do saber" (p. 131). 
No capítulo seguinte, "A atualidade da ficção de Lima Barreto" é tomada, por Maria do Carmo Lanna Figueiredo, desde sua especificidade e a partir de vê-la na contramão do "beletrista" e do "ufanista", onde firmaria a crítica social que faz Lima Barreto. Entre as obras barretianas examinadas e os achados críticos de Maria do Carmo Lanna Barreto, mencionem-se aquelas em que sintetiza as Recordações do escrivão Isaías Caminha, já a partir da plurissignificação do nome do protagonista mestiço: "De certa forma, a voz dupla, entrevista nas recordações, explica a situação do intelectual brasileiro da época e ressoa até os dias de hoje - a do marginalizado que busca, na palavra, a possibilidade de redenção, e que, na ânsia de ser aceito socialmente, reproduz e reduplica a ideologia dominante" (p.144). Finalizando por Clara dos Anjos, este estudo convida a revisitar a obra de Lima Barreto também "enquanto leitura do texto social e do texo cultural" (p. 155).

Quanto a "Dicionário de forquilhas: a poesia de Edimilson de Almeida Pereira”, Maria José Somerlate Barbosa escreve que o poeta, ao "registrar e analisar o universo afro-brasileiro", estaria "desafiando essencialismos nacionalistas que desprezam diferenças regionais e diversidade cultural” (p.159).

Da análise de diversos poemas, pode ser ilustrativa a que apresenta a associação feita por Pereira com os Di-Kishis, figuras mitológicas de duas cabeças, da tradição oral africana, cujas variantes se vêem nas compilações de literatura oral, e que metaforicamente representaria o próprio fazer poético, como concebido por Pereira. A passagem por vários poemas encaminha a que se emoldurem pelas "estratégias de uma linguagem reinventada", o quadro de um "palimpsesto cultural", que a poesia de Pereira constituiria.

Já o capítulo de Maria Nazareth Soares Fonseca ocupa-se de reunir e cotejar amostras literárias, em prosa e verso, em busca de mapear, como diz ela, de perceber e analisar "as marcas discursivas de textos da literatura afro-brasileira e de auscultar as vozes que neles se manifestam, para depreender sentidos abafados, proibidos de se manifestar e reconhecer que a intencionalidade manifesta não se distancia de práticas racistas comuns na sociedade brasileira" (p. 192).

Maria Nazareth aborda um fato literário que analogamente se manifesta nas Literaturas Africanas de Língua Portuguesa e de que podem ser claro exemplo as mulheres cangadas dos espíritos, personagens de contos da cabo-verdiana Orlanda Amarílis para os quais também se requer uma 
específica percepção: "Nos arranjos dos textos, as vozes silenciadas e, como na fala das possuídas, 'alguém outro' organiza sentidos que nem sempre se concretizam na superfície do que as letras parecem dizer" (p. 192).

Em seu trajeto pela prosa e pela poesia, Maria Nazareth passa, também, por observar as ressonâncias de movimentos como Consciência Racial e Renascimento Negro, ligando, assim, fios que poderiam parecer soltos mas que, mesmo mediatamente, imbricam nas formas de resistência da Negritude de Aimé Césaire e Léopold Senghor (p. 204).

Vários são seus pontos de ancoragem entre escritores, nestas águas da literatura afro-brasileira contemporânea, depois de considerar Viva o povo brasileiro, de João Ubaldo Ribeiro: Cuti, Domício Proença Filho, Paulo Colina, Adão Ventura, Marcos Dias, entre outros dos Cadernos Negros, onde ela contempla, também, as mulheres, Esmeralda Ribeiro, Conceição Evaristo, Miriam Alves, tratando, ainda, de Edimilson Pereira.

Seu porto de chegada é, afinal, o da comunhão, no trabalho artístico desses escritores: "Desnudando a revolta sufocada ou recuperando o mundo significado por ritmos e gestos, muitos textos da literatura afro-brasieira exibem-se em transgressão e exploram um léxico operatório que vislumbra alcançar outros sentidos, outros dizeres, outras intenções” (p. 218).

Miriam Alves retoma, no capítulo seguinte, os Cadernos Negros (número 1). Ela os apanha pelo "estado de alerta", no "fogo cruzado", e no contexto em que surge o Movimento Negro Unificado Contra a Discriminação Racial onde aponta a origem dos Cadernos (1978), examinando a significação do "texto-documento" no qual se estabelecem seus pressupostos. Entre os indicadores pelos quais se marcariam os Cadernos, ela rememora como emergiram na "ação incitadora de rebeldia de segmentos da população negra que pretendiam uma ação unificada contra a dita democracia racial que não oportunizava a existência da singularidade e da pluralidade do cidadão negro...” (p. 225).

Depois de colocar também em foco os "críticos, estudiosos e a literatura negra", Miriam Alves fecha o círculo com "legítima defesa”, numa referência, deliberada provavelmente, ao movimento da Légitime Defense, onde conclui: "Quase no número 25 de publicações ininterruptas, Cadernos Negros provou nestas duas décadas e meia que exerceu literariamente a 'legítima defesa dos valores do povo negro' “ (p. 238). 
Poéticas afro-brasileiras remata-se com um texto de Vera Casa Nova, "Da máscara à face negra: em torno de imagens (uma introdução à poética afro-brasileira de Arthur Omar)", no qual os rostos por ele fotografados corresponderiam a poemas visuais, abrindo alternativa de oferecerem-se, inclusive, a uma leitura nos trilhos da antropologia cultural.Sob a inspiração de Roland Barthes, de que a foto é como a palavra, Miriam Alves conclui:

Traduzindo um modo de percepção, uma possibilidade sempre aberta a uma antropologia de cultura visual em que o passado e o presente se cruzam no mito, Arthur Omar dá a ver uma das formas da cultura afrobrasileira - mostrando que a cultura contemporânea, mesmo que centrada no visual, não dissolve o nexo histórico dos fenômenos culturais podendo mesmo resgatá-los através do fotográfico. (p. 254-255)

A leitura de Poéticas afro-brasileiras deixa a convicção final de que é um livro que efetivamente fazia falta nas estantes, também porque abre o devido setor onde localizar um filão da literatura brasileira com o desenvolvimento que tem todas as condições de estender seu produtivo presente ao futuro fecundo de nossa conformação cultural. A metáfora da estante aqui vale para semear o sentido de que poéticas afro-brasileiras, no conjunto de prática e correspondente teoria literária, se pouco estiveram, hão de estar muito presentes, na razão e na e emoção da inteligência brasileira, para ser compartilhada no espaço da cidadania em que caiba qualquer segmento social do Brasil. 